\title{
A PSICOLOGIA EM CONTEXTOS DE EXPRESSÃO DA DESIGUALDADE SOCIAL: DESAFIOS E POSSIBILIDADES
}

Kairon Pereira de Araújo Sousa

Universidade Federal do Piauí - UFPI
Recebido em: 05/04/2020

$1^{\text {a }}$ revisão em: 16/05/2020

Aceito em: 17/05/2020

Santos, L. N. (2014). A psicologia na assistência social: convivendo com a desigualdade. São Paulo, SP: Cortez.

\section{RESENHA}

O livro A psicologia na assistência social: convivendo com a desigualdade resulta da dissertação de mestrado de Luane Neves Santos, na Universidade Federal da Bahia - UFBA. A obra se propõe, a partir da perspectiva sócio-histórica e da noção de compromisso social da psicologia, a refletir sobre a desigualdade social brasileira e sua repercussão na práxis psicológica no Sistema Único de Assistência Social - SUAS, bem como o encontro entre a psicologia e o social.

Para tanto, a autora busca ampliar o debate acerca do tema, apresentando a dimensão subjetiva sobre a desigualdade social, articulando-a a dimensão objetiva que historicamente procurou explicar as causas da desigualdade social a partir de sua relação, especificamente, com os aspectos econômicos. A obra se estrutura em seis capítulos, em sua maioria curtos.

No primeiro capítulo, O princípio da caminhada, a autora faz menção à sua trajetória frente ao tema da desigualdade social, seja como uma brasileira (que também é afetada por este fenômeno), profissional da psicologia ou ainda como pesquisadora. Ademais, referencia as abordagens teóricas, como a da desigualdade social, psicologia sócio-histórica e do compromisso social, responsáveis pela sua implicação com tal objeto de estudo, balizando as direções adotadas, limites e possibilidades de reflexão acerca deste. 
O capítulo seguinte é intitulado A desigualdade social brasileira: uma questão em debate. Neste, a autora procura demonstrar que a desigualdade social é um fenômeno complexo e multifacetado. Para tanto, inicia com uma exposição geral referente à desigualdade social brasileira, apresentando estimativas nacionais, como os dados provenientes do IBGE e o Índice Gini.

Santos discute como a desigualdade social foi se perpetuando em solo brasileiro, tornando-se pouco acessível à percepção (inviabilizada) através de mecanismos como o processo de naturalização, construído pela forte vinculação de ideias tais como: "meritocracia, trajetórias pessoais fracassadas, sorte ou azar" (Santos, 2014, p. 28).

Expondo uma leitura crítica sobre tal fenômeno, a autora trata de questionar a dicotomia presente em diversos estudos referentes ao tema que, ao longo dos anos, contribuíram para uma visão alienante da desigualdade social, sobremaneira pela ênfase majoritária na dimensão objetiva que priorizou uma explicação para as causas da desigualdade salientando aspectos como distribuição da renda, a corrupção, diferenças regionais, etc.

Luane aborda a dimensão subjetiva, trazendo ao debate outras variáveis psicossociais que ampliam a compreensão dessa problemática. Entretanto, ao invés de incorrer na manutenção da dicotomia, propõe a reflexão e discussão da desigualdade social tendo em conta as duas dimensões supracitadas.

Ganha relevo na discussão a apresentação da autora do conceito de má-fé institucional, construto desenvolvido por Jessé Souza, na obra A ralé brasileira: quem é e como vive. Santos emprega tal conceito para esclarecer o leitor a respeito de como o processo de desigualdade social é construído no corpo social. Especificamente, menciona a má-fé institucional em três esferas: escola, justiça e saúde pública.

A má-fé institucional se materializa nessas três esferas da sociedade pelo modo desigual de assistência prestada aos diferentes grupos sociais. O serviço público disponibilizado a grande parcela da população contrasta com o do setor privado, sinalizando a segregação e a classificação hierárquica presente na sociedade brasileira.

Nas páginas seguintes, Santos se dedica a discussão sobre a dimensão subjetiva da desigualdade social, trazendo à baila a teoria de González Rey acerca de tal construto. A autora retrata a carência de produções, no campo da psicologia, relacionadas à dimensão subjetiva da desigualdade social, expondo os resultados de um dos poucos estudos nesta área: pesquisa conduzida por Bock (2010) com homens e mulheres de três bairros diferentes de São Paulo, indicativos de baixo, médio e alto índice de exclusão social.

A Psicologia e o "social" é o título do capítulo três. Aqui, Santos realiza um breve resgate da história da psicologia no Brasil, com o intuito de mostrar como essa 
área (que ao longo de seu itinerário histórico se manteve distante do social, uma vez que priorizou uma atuação voltada para a individualização, pondo-se a serviço dos interesses das camadas mais abastadas da sociedade) foi gradativamente se aproximando do social.

A autora salienta algumas mudanças na sociedade brasileira que contribuíram para esta transformação no enfoque da psicologia. São elas: a promulgação da Constituição Federal de 88; mudanças no mercado de trabalho na psicologia e a emergência de produções acadêmicas advogando em prol de uma psicologia com compromisso social.

O capítulo quatro é intitulado O SUAS como espaço de trabalho das psicólogas. $\mathrm{Na}$ parte inicial do texto, a autora procura esclarecer ao leitor o motivo do emprego da expressão "psicólogas" ao invés do convencional e genérico termo "psicólogo". Sumariza, para tanto, dados do Conselho Federal de Psicologia (CFP), que datam de 2011, para apontar um número maior de mulheres na profissão.

Menciona também uma supremacia masculina na categoria referente à ocupação de cargos de destaque, pelo que justifica a necessidade de se discutir esses atravessamentos, motivando-a a empregar tal expressão no capítulo. Entretanto, a partir da leitura desta parte do livro, o leitor constatará que, apesar de indicar o uso do termo no feminino, ao longo do texto Santos acaba recorrendo à forma masculina, mesmo em trechos que não figuram como citação.

São pontos principais abordados no presente capítulo: (1) o processo de constituição da Assistência Social como política pública - a autora discute como a assistência anteriormente efetuada como prática de caridade ou benemerência foi se transformando em política de estado, direcionada a todos aqueles que dela necessitarem, sem contribuição prévia, materializando-se em equipamentos da proteção social básica (CRAS) e especial (CREAS) -; (2) atuação em psicologia no SUAS enfatiza-se os desafios, limites e possibilidades de atuação em psicologia no CRAS/SUAS.

O capítulo cinco (o mais longo do livro, com 52 páginas no total) traz como título: O encontro das psicólogas com o "social": campos de expressão das desigualdades. É a parte do livro que apresenta os resultados da pesquisa em campo, ou seja, a parte empírica do estudo.

Tendo isso em conta, Santos inicia situando o leitor a respeito do objetivo do estudo, bem como do método empregado. Quanto a este, é realizada uma caracterização pormenorizada, descrevendo-se os instrumentos, os participantes da pesquisa, o local do estudo e a análise de dados. A autora sumariza quatro eixos temáticos que nortearam a pesquisa, permitindo a coleta, organização e discussão dos dados.

O primeiro versa sobre os aspectos da biografia das participantes, objetivando situá-las a partir do "lugar de fala". Estão incluídas, portanto, as variáveis 
sociodemográficas, a exemplo de: sexo, idade, escolaridade, estado civil, religião e dados referentes à transição socioeconômica da família.

O segundo eixo aborda a trajetória acadêmica das entrevistadas, procurando investigar como se deu a entrada destas no dispositivo CRAS; os suportes obtidos durante a formação para atuação em situações de pobreza decorrente da desigualdade social, como disciplinas, cursos, etc. O terceiro eixo foca a atuação das psicólogas no CRAS (atividades realizadas). São apresentadas as limitações encontradas pelas profissionais no cotidiano de trabalho com parcelas pobres da população.

Estas podem ser agrupadas em duas: dificuldades relativas à formação acadêmica e de ordem institucional (aqui, a autora retoma o conceito de má-fé institucional, apresentado no capítulo 2, para refletir sobre a precarização das condições de trabalho das psicólogas no dispositivo CRAS). Enfatiza-se também as frustações destas profissionais em relação a este campo de atuação e suas pretensões relativas à permanência ou não na área. Por fim, o quatro eixo explora a explicação atribuída pelas profissionais para o fenômeno da desigualdade social, evidenciando suas percepções relativas ao público-alvo do serviço.

No último capítulo do livro, Por uma atuação com compromisso social, Santos apresenta as considerações finais, retomando e refletindo acerca dos principais achados evidenciados nos quatro eixos anteriores. Nele, o leitor perceberá que a autora enfatiza a atuação das psicólogas entrevistadas junto às camadas menos abastadas da sociedade, ressaltando a falta de apropriação, pelas profissionais, de referenciais teóricos capazes de fomentar uma atuação mais crítica e voltada para o compromisso social. Esse déficit, segundo a autora, contribui para uma visão naturalizante acerca da desigualdade social, bem como para uma práxis marcada pelo preconceito e alienação frente ao público atendido.

O livro aqui resenhado traz contribuições para a área, sobretudo ao discutir o fenômeno da desigualdade social estampada de várias formas nos CRAS a partir de uma ótica que contrapõe as explicações superficiais e genéricas que a associam apenas a questões de ordem objetiva. Ademais, representa uma das poucas obras disponíveis ao público leitor que discute a atuação de psicólogos nesses dispositivos da assistência social, avaliando como estes profissionais percebem e desenvolvem suas práxis em meio a um contexto de vulnerabilidade, onde o fenômeno da desigualdade social se torna mais evidente.

Além destes pontos mencionados acima, pode-se citar como uma das grandes contribuições do livro a exposição do conceito de má-fé institucional. A apropriação deste construto por psicólogos que atuam com populações que vivenciam situações de extrema desigualdade social é relevante para o desenvolvimento de uma ação consistente e direcionada a um projeto de compromisso social na psicologia, na qual estes espaços públicos (CRAS) sejam tomados como dispositivos de transformação social. Diante disso, recomenda-se 
a leitura desta obra aos estudantes, profissionais, professores e pesquisadores da psicologia.

\section{CONFLITOS DE INTERESSES}

Não há conflitos de interesse.

\section{SOBRE OS AUTORES}

Kairon Pereira de Araújo Sousa é psicólogo pela Universidade Estadual do Piauí e mestre em psicologia (Processos Psicossociais) pelo Programa de Pós-Graduação em Psicologia da Universidade Federal do Piauí. Trabalha como psicólogo social e desenvolve pesquisa na área da psicologia e sua avaliação em diferentes contextos psicossociais. É membro colaborador do Núcleo de Pesquisa do Laboratório de Avaliação Psicológica do Delta do Parnaíba - LABAP-UFPI.

e-mail: kaironpereira@hotmail.com

(2) https://orcid.org/0000-0003-0779-343X 